\title{
Introduction to RIETI
}

The Research Institute of Economy, Trade and Industry (RIETI), an incorporated administrative agency, was established on 1 April, 2001 to conduct wide-ranging policy research and formulate policy recommendations. RIETI capitalizes on its location in Tokyo's Kasumigaseki district, the political and economic nerve center of Japan, to take full advantage of the synergy between policy-makers, researchers, industry leaders and other stakeholders. RIETI promotes policy formulation backed by theoretical and analytical research from a global perspective, not restricted to traditional approaches, with the ultimate goal of building a mature and dynamic Japanese society. To this end, RIETI has established research domains that respond to Japan's economic and industrial policy needs, within which individual research projects interact organically. To disseminate research results and promote policy recommendations effectively, RIETI makes aggressive use of its website, printed publications and a variety of other tools. RIETI pledges to continue to influence policy debate and policymaking through continually active delivery of policy recommendations. For more information, please visit http://www.rieti.go.jp/en/index.html. 
Dale Jorgenson, Masahiro Kuroda, and Kazuyuki Motohashi - 9781847208743 Downloaded from PubFactory at 04/26/2023 11:33:36AM 